\title{
COVID-19 in patients with gout on colchicine
}

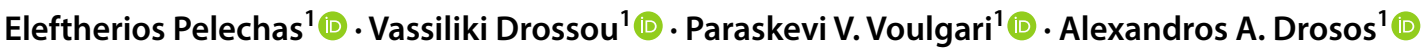

Received: 17 April 2021 / Accepted: 20 May 2021 / Published online: 5 June 2021

(c) The Author(s), under exclusive licence to Springer-Verlag GmbH Germany, part of Springer Nature 2021

\begin{abstract}
Current data demonstrated that severe cases of coronavirus-disease-19 (COVID-19) require treatment with antiviral therapy, dexamethasone, supportive care, as well as some anti-rheumatic drugs, among them, cytokine inhibitors and colchicine. Colchicine is an anti-inflammatory drug that is being used in rheumatology for many years to treat mostly gout, calcium pyrophosphate deposition disease, and Familial Mediterranean Fever. Here, we present for the first time, two patients suffering from gout being treated with colchicine, who were affected from severe acute respiratory coronavirus-2 (SARS-CoV-2) syndrome. Both patients presented with mild symptoms of COVID-19 expressed with myalgias, arthralgias, and sore throat, while laboratory investigations showed only high acute phase reactants. Four weeks later, both patients were free of symptoms with negative SARS-CoV-2 tests and without any complications. To our knowledge, there are no other studies of gout arthritis and SARS-CoV-2 infection published so far. Thus, our preliminary conclusion is that chronic use of colchicine may mitigate the clinical picture and disease course of COVID-19 in gout arthritis patients. Further studies with a large number of patients are needed to confirm the above beneficial effect of colchicine.
\end{abstract}

Keywords COVID-19 $\cdot$ Colchicine $\cdot$ Gout arthritis $\cdot$ Systemic inflammation $\cdot$ Cytokine inhibitors $\cdot$ Inflammasome

\section{Introduction}

Systemic inflammation is the hallmark of severe coronavirus disease-19 (COVID-19), in which high levels of proinflammatory cytokines, such as interleukin (IL)-1 $\beta$, IL-6, $\mathrm{IL}-18$, and tumor necrosis factor alpha (TNFa), are some of the immunological disturbances occurring in this setting. The global COVID-19 caused by the severe acute respiratory syndrome coronavirus-2 (SARS-CoV-2) is a matter of concern and a huge challenge to rheumatologists, especially for patients suffering from autoimmune rheumatic diseases

Alexandros A. Drosos

adrosos@uoi.gr

http://www.rheumatology.gr

Eleftherios Pelechas

pelechas@ doctors.org.uk

Vassiliki Drossou

drossou.v@gmail.com

Paraskevi V. Voulgari

pvoulgar@uoi.gr

1 Rheumatology Clinic, Department of Internal Medicine, Medical School, University of Ioannina, 45110 Ioannina, Greece
(ARD) $[1,2]$. SARS-CoV-2 infection has been proven to affect mostly the vulnerable population, elderly, and patients with ARD [1, 3, 4]. For severe cases of COVID-19, treatment requires antiviral therapy, dexamethasone, supportive care, as well as some anti-rheumatic drugs, in an attempt to control the immune activation. Among the anti-rheumatic drugs, cytokine inhibitors and colchicine have been used in several cases $[5,6]$. Over the last 6 months, several studies demonstrated that conventional synthetic (cs) disease-modifying anti-rheumatic drugs (DMARDs) and/or biological (b) DMARDs, especially cytokine inhibitors, could reduce the risk of severe disease and complications related to cytokine storm [7-10]. On the other hand, moderate-to-high doses of prednisone ( $>10 \mathrm{mg} /$ day) as well as other immunosuppressive drugs including rituximab are associated with hospitalization of severe COVID-19 disease and death [11, 12]. Colchicine is an anti-inflammatory drug that has been used in rheumatology for many years to treat mostly gout, calcium pyrophosphate deposition disease (CPPD), and Familial Mediterranean Fever (FMF). Treatment with colchicine for COVID-19 is a matter of discussion. There are studies leading to the hypothesis that colchicine might be a safe and effective treatment for COVID-19 disease [13, 14], and others arguing against it [15]. To investigate whether colchicine 
is effective against COVID-19 disease, we present two patients with gout arthritis receiving regularly colchicine that contracted SARS-CoV-2, and we discuss the relevant literature. A written informed consent has been obtained and signed by both patients. All procedures were in accordance with ethical standards and the 1975 Helsinki Declaration, as revised in 2000 .

\section{Case presentation 1}

A 45-year-old male patient has been followed up since 2017 due to hyperuricemia (uric acid $9 \mathrm{mg} / \mathrm{dl}$ ). On September 2020, he had an acute gout attack affecting the first metatarsophalangeal joint of his right foot. Past medical and family history were unremarkable. He was smoker. Blood pressure was 120/75 $\mathrm{mmHg}$, and his body weight was $98 \mathrm{~kg}$. Laboratory tests showed high erythrocyte sedimentation rate (ESR): $51 \mathrm{~mm} / \mathrm{h}$ and C-reactive protein (CRP) $16 \mathrm{mg} / \mathrm{dl}$ (normal values $<5$ ). He was treated with naproxen $500 \mathrm{mg}$ bid, and 5 days later, he was symptom-free. However, after 1 month, he presented with a new flare. Naproxen $500 \mathrm{mg}$ bid was started once again, but this time colchicine $0.5 \mathrm{mg}$ bid was also added. A week later, a complete clinical response has been achieved allowing him to discontinue the naproxen tablets. He carried on with colchicine, but allopurinol at a dosage of $300 \mathrm{mg} /$ day has been also added. Thenceforth, he did not have any new gout attacks. On February 28 2021, he presented myalgias, arthralgias, and low-grade fever $\left(37.5^{\circ} \mathrm{C}\right)$. He had no signs of arthritis and was positive for SARS-CoV-2 after a polymerase chain reaction (PCR) test. He could not recall of being exposed, or to have been in contact with other symptomatic or affected individuals with SARS-CoV-2. Laboratory tests were normal except of an increased ESR and CRP. Chest X-rays were normal. He remained isolated at home receiving colchicine. A week later, he felt much better, his symptoms gradually resolved, and a test for SARS-CoV-2, 4 weeks apart, was negative. Two months later, he was still asymptomatic without any COVID-19 complications.

\section{Case presentation 2}

A 50-year-old male with recurrent attacks of gout arthritis since 2018 presented on March 32021 with sore throat, myalgias, arthralgias, as well as loss of taste and smell. He was positive for SARS-CoV-2 after a rapid and subsequently a PCR test. He did not have any suspicious contacts from his family or work environment. Past medical history was positive for hypertension treated with losartan. Family history was negative. He was on allopurinol $300 \mathrm{mg}$ OD plus colchicine $0.5 \mathrm{mg}$ BID with no frank arthritis. Laboratory investigation showed increased ESR and CRP, while the rest of the laboratory tests were within normal limits, or negative. Chest X-ray was normal. He stayed at home, without any additional therapy, while he continued receiving colchicine. Ten days later, he felt well without myalgias, arthralgias, or sore throat, but the olfactory symptoms were still present. After 1 week, he was free of his symptoms with some improvement of the olfactory dysfunction, and after 4 weeks, a new test for SARS-CoV-2 was negative. Two months later, he felt very well with further improvement of olfactory dysfunction without any new COVID-19 consequences.

\section{Discussion}

In this report, we present for the first time two patients suffering from gout being treated with colchicine, who were affected from SARS-CoV-2. Both patients presented mild systemic manifestations with myalgias, arthralgias, and sore throat, while the laboratory investigation showed only high acute phase reactants. For severe cases of SARS-CoV-2 infection, treatment requires antiviral therapy, dexamethasone, supportive care, and the use of some anti-rheumatic drugs, in an attempt to control the immune activation. Among those drugs is colchicine.

Colchicine is a tricyclic alkaloid extracted from the plant Colchicum autumnale. Colchicine is a potent antiinflammatory agent that is being used in rheumatology for many years to treat gout, calcium pyrophosphate deposition disease (CPPD), and Familial Mediterranean Fever (FMF) [16-18]. It is also used in cardiology for viral pericarditis and other cardiovascular diseases [19]. Recent studies showed that by adding colchicine to the standard care of patients hospitalized with severe COVID-19 disease, there is a beneficial effect on disease outcomes [14, 19-22]. At this point, the question which arises is how colchicine could help patients suffering from SARS-CoV-2 infection? The answer is simple. We do not know yet. However, we do know that colchicine is a potent inhibitor of tubulin polymerization. Microtubules are the main tools of cytoskeleton which are involved in many cellular processes, such as maintaining the shape of the cell, transferring intracellular substances, cell migration, cell division, secretion of cytokines, but also many others [16-18]. Furthermore, colchicine has an inhibitory effect on chemotaxis of inflammatory cells (neutrophils and monocytes), and inhibits the expression of adhesion molecules in the setting of inflammation, resulting in a decreased production of pro-inflammatory cytokines and free radicals like superoxide [16-18]. It also inhibits the NOD Like Receptor Protein-3 (NLRP3) inflammasome, suppressing caspase-1 activation resulting in inhibition of IL-1 $\beta$, IL-6, TNFa, IL-18, and various chemokines [23]. 


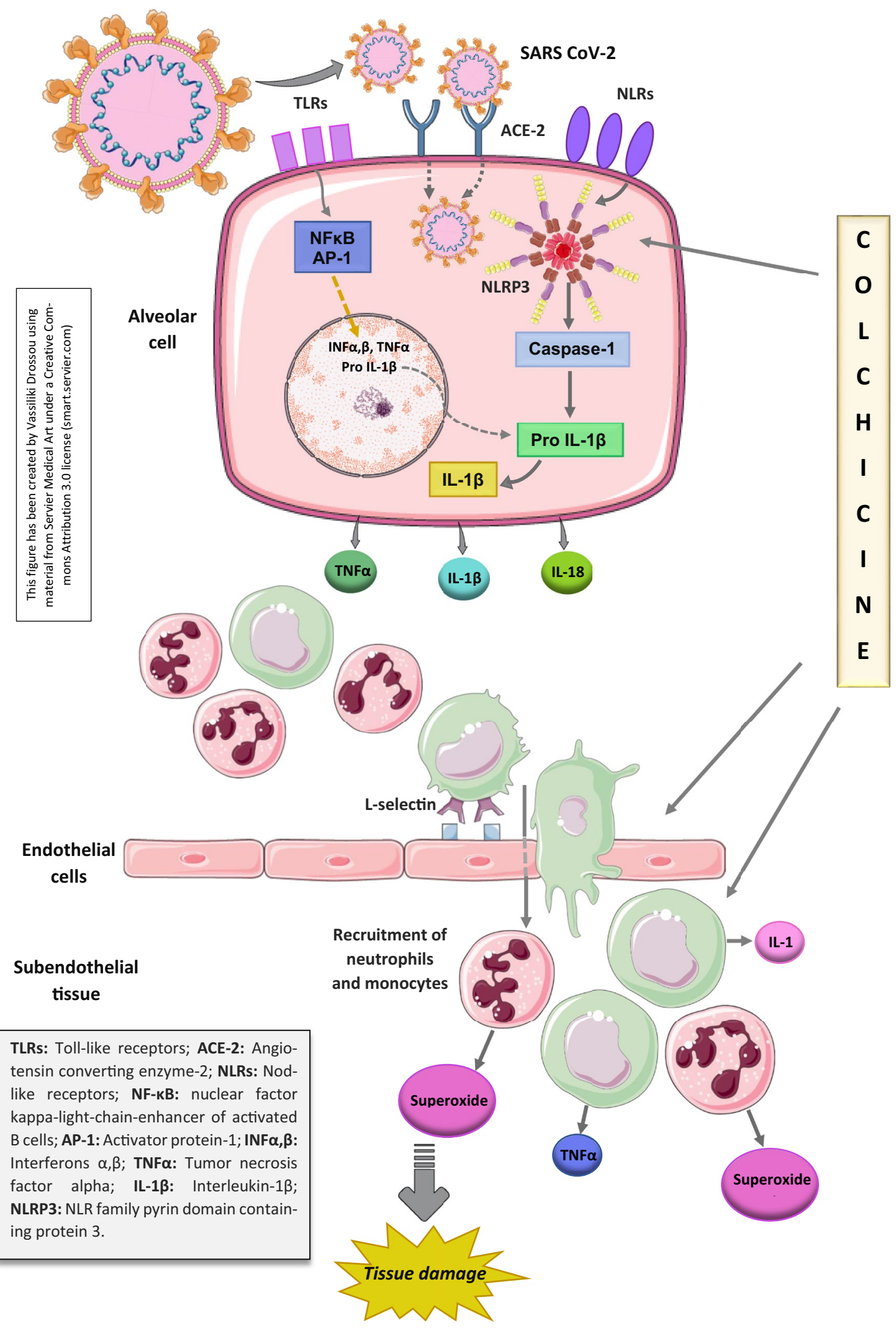

Fig. 1 Schematic representation of COVID-19 disease pathophysiology and colchicine actions 
Thus, we can speculate that when SARS-CoV-2 affects the alveolar cells via the Angiotensin Converting Enzyme-2 (ACE-2) receptor, activation of the inflammasome NLRP3 occurs, leading to activation of caspase- 1 and the production of IL- $1 \beta$ and other cytokines into the cells $[24,25]$. The release of these cytokines is responsible for the COVID-19 disease expression and outcome. Secreted cytokines cause activation of endothelial cells, overexpression of adhesion molecules, recruitment of leucocytes (neutrophils and monocytes), which invade the sub-endothelial tissue with further production of pro-inflammatory cytokines and chemokines, as well superoxide amines with augmentation of inflammation, leading to tissue damage (Fig. 1). On the other hand, colchicine inhibits the NLRP3 inflammasome suppressing the caspase- 1 activation, resulting on inhibition of signaling pathways involving the intracellular production of cytokines and chemokines. Moreover, it inhibits the expression of adhesion molecules and leucocyte recruitment with further cytokine reduction and inflammatory load [25] (Fig. 1).

The above mechanisms may explain in part the fact that our patients with gout receiving colchicine had mild symptoms of COVID-19 disease. Another factor which may influences the mild clinical manifestations in our patients is that they had no other severe comorbidities except obesity and hypertension, respectively, and were relatively young. In line with our results is a case published recently by Kobak $\mathrm{S}$, who reported a patient with FMF receiving colchicine, who was affected from SARS-CoV-2 infection. The patient had only mild symptoms of the disease such as myalgias and arthralgias without severe respiratory manifestations and recovered without any additional treatment [26]. Other investigators concluded that patients with FMF receiving a long-term treatment with colchicine had no additional risk factors after severe COVID-19 disease, as compared with the general population [27]. There are no other studies of gout arthritis and SARD-CoV-2 infection published so far.

Our preliminary conclusion is that the chronic use of colchicine may mitigate the clinical picture and disease course of COVID-19 in gout arthritis patients. The above conclusion is based in only two case reports, which is the main limitation of our study. However, given the large body of evidence showing colchicine's inhibitory effects on cytokine generation, neutrophil activity, and adhesion molecules in the setting of inflammation, it seems rational to study colchicine as a potential treatment for SARS-CoV-2 infection. Thus, further studies with a large number of patients are required to confirm the above beneficial effect of colchicine.

Acknowledgements We would like to thank Ms Areti Fili for the excellent secretary assistance.

Author contribution All authors have made substantial contributions to the current manuscript and approved the final version fulfilling all the four criteria proposed be the ICMJE. EP and VD: drafting; PVV: revision; AAD: conception of the work and revision; All authors are stating that the article has not been published and is not under consideration for publication elsewhere.

Funding This research did not receive any specific grant from funding agencies in the public, commercial, or not-for-profit sectors.

\section{Declarations}

Conflict of interest All authors declare that they have no conflict of interest.

\section{References}

1. Zhou F, Yu T, Du R, Fan G, Liu Y, Liu Z et al (2020) Clinical course and risk factors for mortality of adult inpatients with COVID-19 in Wuhan, China: a retrospective cohort study. Lancet 395:1054-1062. https://doi.org/10.1016/S0140-6736(20)30566-3

2. Robinson PC, Yazdany J (2020) The COVID-19 global rheumatology alliance: collecting data in a pandemic. Nat Rev Rheumatol 16:293-294. https://doi.org/10.1038/s41584-020-0418-0

3. Wang T, Du Z, Zhu F, Cao Z, An Y, Gao Y et al (2020) Comorbidities and multi-organ injuries in the treatment of COVID-19. Lancet 395:e52. https://doi.org/10.1016/S0140-6736(20)30558-4

4. Sepriano A, Kerschbaumer A, Smolen JS, van der Heijde D, Dougados M, van Vollenhoven R et al (2020) Safety of synthetic and biological DMARDs: a systematic literature review informing the 2019 update of the EULAR recommendations for the management of rheumatoid arthritis. Ann Rheum Dis 79:760-770. https://doi. org/10.1136/annrheumdis-2019-216653

5. Ferro F, Elefante E, Baldini C, Bartoloni E, Puxeddu I, Talarico $R$ et al (2020) COVID-19: the new challenge for rheumatologists. Clin Exp Rheumatol 38:175-180

6. Pelechas E, Drossou V, Voulgari PV, Drosos AA (2020) Antirheumatic drugs for the fight against the novel coronavirus infection (SARS-CoV-2): what is the evidence? Mediterr J Rheumatol 31:259-267. https://doi.org/10.31138/mjr.31.3.259

7. Gianfrancesco M, Hyrich KL, Al-Adely S, Carmona L, Danila MI, Gossec L et al (2020) Characteristics associated with hospitalization for COVID-19 in people with rheumatic disease: data from the COVID-19 global rheumatology alliance physician-reported registry. Ann Rheum Dis 79:859-866. https://doi.org/10.1136/ annrheumdis-2020-217871

8. Monti S, Balduzzi S, Delvino P, Bellis E, Quadrelli VS, Montecucco C (2020) Clinical course of COVID-19 in a series of patients with chronic arthritis treated with immunosuppressive targeted therapies. Ann Rheum Dis 79:667-668. https://doi.org/ 10.1136/annrheumdis-2020-217424

9. Haberman RH, Castillo R, Chen A, Yan D, Ramirez D, Sekar V et al (2020) COVID-19 in patients with inflammatory arthritis: a prospective study on the effects of comorbidities and diseasemodifying antirheumatic drugs on clinical outcomes. Arthritis Rheumatol 72:1981-1989. https://doi.org/10.1002/art.41456

10. Migkos MP, Kaltsonoudis E, Pelechas E, Drossou V, Karagianni PG, Kavvadias A (2021) Use of conventional synthetic and biologic disease- modifying anti-rheumatic drugs in patients with rheumatic diseases contracting COVID-19: a single-center experience. Rheumatol Int Mar 3:1-7. https://doi.org/10.1007/ s00296-021-04818-2

11. Hyrich KL, Machado PM (2021) Rheumatic disease and COVID19: epidemiology and outcomes. Nat Rev Rheumatol 17:71-72. https://doi.org/10.1038/s41584-020-00562-2 
12. Strangfeld A, Schafer M, Gianfrancesco MA, Lawson-Tovey S, Liew JW, Ljung L et al (2021) Factors associated with COVID19-related death in people with rheumatic diseases: results from the COVID-19 global rheumatology alliance physicianreported registry. Ann Rheum Dis. https://doi.org/10.1136/annrh eumdis-2020-219498

13. US National Library of Medicine. Clinical Trials. Colchicine coronavirus SARS-CoV-2 Trial (COLCORONA) (COVID-19). NCT04322682. https://clinicaltrials.gov/ct2/show/NCT04322682. Accessed Mar 2021

14. Deftereos SG, Giannopoulos G, Vrachatis DA, Siasos GD, Giotaki SG, Gargalianos P et al (2020) Effect of colchicine vs standard care on cardiac and inflammatory biomarkers and clinical outcomes in patients hospitalized with coronavirus disease 2019: the GRECCO-19 randomized clinical trial. JAMA Netw Open 3:e2013136. https://doi.org/10.1001/jamanetworkopen.2020. 13136

15. Cure MC, Kucuk A, Cure E (2020) Colchicine may not be effective in COVID-19 infection; it may even be harmful? Clin Rheumatol 39:2101-2102. https://doi.org/10.1007/s10067-020-05144-x

16. Sobodnick A, Shah B, Pillinger MH, Krasnokutsky S (2015) Colchicine: old and new. Am J Med 128:461-470. https://doi.org/10. 1016/j.amjmed.2014.12.010

17. Leung YY, Hui LLY, Kraus VB (2015) Colchicine-update on mechanisms of action and therapeutic uses. Semin Arthritis Rheum 45:341-350. https://doi.org/10.1016/j.semarthrit.2015.06. 013

18. Slobodnick A, Shah B, Krasnokutsky S, Pillinger MH (2018) Update on colchicine, 2017. Rheumatology (Oxford) 57:i4-i11. https://doi.org/10.1093/rheumatology/kex453

19. Deftereos S, Giannopoulos G, Papoutsidakis N, Panagopoulou V, Kossyvakis C, Raisakis K et al (2013) Colchicine and the heart: pushing the envelope. J Am Coll Cardiol 62:1817-1825. https:// doi.org/10.1016/j.jacc.2013.08.726

20. Vrachatis DA, Giannopoulos GV, Giotaki SG et al (2020) Impact of colchicine on mortality in patients with COVID-19: a meta- analysis. Hellenic J Cardiol. https://doi.org/10.1016/j.hjc. 2020.11.012

21. Deftereos S, Giannopoulos G, Vrachatis DA, Siasos G, Giotaki SG, Cleman M et al (2020) Colchicine as a potent anti-inflammatory treatment in COVID-19: can we teach an old dog new tricks? Eur Heart J Cardiovasc Pharmacother 6:255. https://doi.org/10. 1093/ehjcvp/pvaa033

22. Lopes MI, Bonjorno LP, Giannini MC, Amaral NB, Menezes PI, Dib SM et al (2021) Beneficial effects of colchicine for moderate to severe COVID-19: a randomized, double-blinded, placebocontrolled clinical trial. RMD Open 7:e001455. https://doi.org/ 10.1136/rmdopen-2020-001455

23. Cookson BT, Brennan MA (2001) Pro-inflammatory programmed cell death. Trends Microbiol 9:113-114. https://doi.org/10.1016/ s0966-842x(00)01936-3

24. Chen IY, Moriyama M, Chang MF, Ichinohe T (2019) Severe acute respiratory syndrome coronavirus viroporin $3 \mathrm{a}$ activates the NLRP3 inflammasome. Fron Microbiol 10:50. https://doi.org/10. 3389/fmicb.2019.00050

25. Reyes AZ, Hu KA, Teperman J, Muskardin TLW, Tardif JC, Shah B, Pillinger MH (2021) Ann Rheum Dis 80:550-557. https://doi. org/10.1136/annrheumdis-2020-219174

26. Kobak S (2021) COVID-19 infection in a patient with FMF: does colchicine have a protective effect? Ann Rheum Dis 80:e39

27. Bourguiba R, Delplanque M, Vinit $C$ et al (2021) Clinical course of COVID-19 in a cohort of 342 familial Mediterranean fever patients with a long-term treatment by colchicine in a French endemic area. Ann Rheum Dis 80:539-540. https://doi.org/10. 1136/annrheumdis-2020-218707

Publisher's Note Springer Nature remains neutral with regard to jurisdictional claims in published maps and institutional affiliations. 